\title{
Factors Determining the Restoration of Circadian Behavior by Hypothalamic Transplants
}

\author{
Michael A. Vogelbaum, Jennifer Galef* and Michael Menaker* \\ Departments of Biology and Biomedical Engineering, ${ }^{*}$ Department of Biology \\ and Center for Biological Timing, University of Virginia, Charlottesville, VA 22901, USA
}

\begin{abstract}
The expression of locomotor activity by golden hamsters is temporally controlled by circadian oscillators contained within the suprachiasmatic nucleus (SCN). A genetic mutation has been found that alters the freerunning period of the locomotor activity rhythm from the wild-type value of $\sim 24$ hours to 20 hours in homozygous mutants. It has been shown previously that a transplant of fetal hypothalamic tissue containing the SCN to a host rendered arrhythmic by a complete lesion of the SCN restores rhythmicity with the freerunning period which is normally expressed by the donor genotype. To investigate the mechanisms by which the SCN controls the temporal organization of behavior, we made partial lesions to the SCN of hosts of one genotype, and then placed hypothalamic implants from fetal donors of a different genotype into the lesion site. By varying the size of the host's partial SCN lesion and the duration of time between lesioning and transplantation, we have attempted to alter the relative amount of host and donor control over the expression of locomotor activity. We found that the expression of donor rhythmicity requires the presence of a lesion to the host SCN, and that the incidence of donor expression increased as a function of host SCN lesion size. Neither the duration of time between lesioning and transplantation, nor the location of the transplant within the third ventricle had independent effects on the
\end{abstract}

Reprint address:

M.A. Vogelbaum

Department of Biology

Gilmer Hall

University of Virginia

Charlottesville, Virginia 22901, USA incidence of donor rhythm expression; however, there was a strong suggestion of an effect of their interaction.

\section{KEY WORDS}

suprachiasmatic nucleus, circadian rhythms, golden hamster, neural transplants

\section{INTRODUCTION}

The circadian oscillators responsible for the temporal control of locomotor activity in mammals are located in the suprachiasmatic nucleus (SCN) of the hypothalamus. While these oscillators normally cycle with periods close to 24 hours, a spontaneously occurring autosomal mutation has been found in the golden hamster (Mesocricetus auratus) which alters the value of the freerunning period $/ 16 /$. Hamsters carrying the heterozygous form of this mutation, called Tau $(\tau)$, express circadian rhythms having freerunning periods close to 22 hours; homozygotes have periods close to 20 hours. Complete lesions of the SCN result in circadian arrhythmicity in both rats and hamsters $112,18,19,25 /$. Lesions that destroy only a portion of these nuclei ('partial lesions') result in disrupted, but clearly rhythmic activity patterns /7,14/. Transplants of fetal hypothalamus containing cells from the SCN restore locomotor rhythmicity to fully SCN lesioned, arrhythmic hosts $/ 5,6,10,20,21 /$ with periods corresponding to those expected from the genotype of the donor $/ 15 /$. The mechanisms by which the circadian oscillators in the SCN exert control over the expression of locomotor activity remain to be determined.

One method to investigate the ways in which the locomotor output system of hamsters processes 
its circadian inputs is experimentally to subject the locomotor output system to multiple inputs. Observation of the resulting locomotor behaviors can provide insight into the ways in which the circadian system controls the temporal organization of locomotor activity. We transplanted fetal SCN tissue from donors of one genotype into partially lesioned adult hosts of a different genotype. By varying the size of the host SCN lesion and the elapsed time between lesioning and transplantation, we attempted to vary the relative amount of host and donor input to the locomotor output system. These experiments produced hamsters which expressed two different freerunning periods; we have called these animals 'temporal chimeras'. While many temporal chimeras express both host and donor circadian rhythms simultaneously in their locomotor activity behavior, others show alternation between expression of host and donor rhythms $/ 27 /$. Not all of the animals that received implants expressed both host and donor rhythms, however. In this study we examined the effects of lesion size and elapsed time between lesioning and implantation on the integration of host and donor circadian inputs by the locomotor output system of animals which received partial lesions and transplants.

\section{MATERIALS AND METHODS}

The methods for performing SCN lesions, preparing SCN implants, and performing transplantation have been described in detail previously $/ 27 /$. Briefly, SCN lesions were made in each deeply anesthetized potential host hamster using a platinum-iridium lesioning electrode. A $4 \mathrm{~mA}$ current was passed for $2.5,5,10$ or 15 seconds, thereby producing graded amounts of damage to the SCN. Implants were prepared from the litters of homozygous mutant $\left(\tau_{s s}\right)$ or wild-type $\left(\tau_{\mathrm{w} t}\right)$ hamsters. Fetuses were removed by cesarean section from deeply anesthetized pregnant females at 13.5 to 14 days after mating. A block of tissue containing the SCN was removed from each fetal brain and was stored in a mixture of $(60 \%)$ Basal Eagle's Medium with Earle's Salts and (40\%) Hanks' Balanced Salt Solution (Gibco) in an incubator maintained at $36^{\circ} \mathrm{C}$. The time from the start of preparation of implants to completion of all transplantations was kept under 2 hours. For transplantation, one or two implants were drawn into a $5 \mu \mathrm{l}$ Wiretrol capillary tube (Drummond Scientific Co., PA) along with culture solution so that the total volume did not exceed $2 \mu l$. The capillary tube and its plunger were mounted on a cannula guide and lowered through the craniotomy to the original coordinates for the SCN. The implant was completely ejected using a pressure-free technique and the tube and plunger were removed and the wound was closed. Some implants were placed into hamsters that had no prior SCN lesion.

\section{Locomotor activity recording}

Host hamsters were individually maintained in cages equipped with a running wheel, and with food and water ad libitum. Six cages were kept in a lighttight box and each animal's running wheel activity was recorded remotely using the Dataquest (DSI, MN) computer-based data acquisition system. All hamsters were kept in constant darkness (DD) except at times of surgery. The data were collected as the number of running-wheel revolutions per six minute bin. They were analyzed and plotted off-line using our own software. We recorded the running wheel activity of each hamster starting before the SCN lesion and continuing for at least 3 months after transplantation.

\section{Experimental design}

Animals were subjected to one of five experimental conditions: 1) $\tau_{\mathrm{wt}}$ hosts received fetal $\tau_{\text {ss }}$ SCN transplants immediately after an SCN lesion was made ('immediate'); 2) $\tau_{\mathrm{wt}}$ hosts received fetal $\tau_{\text {ss }}$ SCN transplants 3 to 5 weeks after an SCN lesion was made ('delayed'); 3 ) $\tau_{\mathrm{ss}}$ hosts received immediate fetal $\tau_{\mathrm{wt}}$ SCN transplants; 4) $\tau_{\mathrm{ss}}$ hosts received delayed fetal $\tau_{\mathrm{wt}}$ SCN transplants, and 5) $\tau_{w t}$ hosts received $\tau_{s s}$ implants without having received a prior SCN lesion. A partial SCN lesion was made in each hamster in the first 2 groups using a current duration of $2.5,5,10$ or 15 seconds. Those in groups 3 and 4 were given lesions using current durations of 5,10 , or 15 seconds. 
Each animal's locomotor activity was recorded for about 3 months after transplantation, after which time the entire running record was examined for the presence of host and/or donor rhythms. It has been shown previously that the genotype of an individual hamster can be identified by measuring the freerunning circadian period of its locomotor activity rhythm, because each phenotype expresses circadian rhythms with a non-overlapping period distribution $/ 15,16 /$. Therefore, we were able to identify the source (i.e. host or donor) of each rhythm expressed simply by determining its period.

A separate group (lesion size group) of $19 \tau_{\mathrm{wt}}$ hamsters was used to verify the assumption that current duration determines the size of the SCN lesion. These animals were subjected to either sham (0), 2.5, 5, 10, or 15 second lesions. Their running wheel activity data were recorded for 3-4 weeks and then the animals were sacrificed for histological analysis.

\section{Evaluation of rhythmicity}

The entire locomotor activity of each hamster was evaluated visually for the presence of $\sim 24$ hour and/or $\sim 20$ hour rhythms, with the use of actograms double-plotted on both 24 and 20 hour time-bases. We have previously described two patterns of rhythmic activity expressed by temporal chimeras $127 /$. For this analysis, as in our earlier work, we considered that a circadian rhythm generated by either host or donor oscillators was present when one of two criteria was met: 1) a series of wheelrunning events recurred at approximately the same phase each cycle and occurred for at least 5 consecutive cycles, or 2 ) there existed a specific phase at which activity did not occur (a 'window' that delineated the temporal boundaries of expressed locomotor activity) that was consistent over at least 20 cycles. Using these criteria, a positive or negative $(\mathrm{Y} / \mathrm{N})$ evaluation was given for the appearance of 24 hour or 20 hour rhythms in the record before and after the fetal SCN transplant was placed into the host. Importantly, it was not necessary for a rhythm to persist throughout the entirety of the record for it to be considered present; for example, in a number of records rhythms with periods of 24 or 20 hours alternately appeared and disappeared over the course of an experiment $/ 27 /$. Although we had no difficulty detecting rhythms meeting the first criterion using quantitative techniques such as periodogram /24/ or Fourier power spectral analysis, we found these techniques to be less sensitive to those rhythms that fit the second criterion. Nevertheless, window rhythms were consistently identified by naive observers visually evaluating actograms using the criteria described above.

We used 1 and 2-way ANOVA (Systat) to test the null hypotheses that lesion current duration and/or length of time interval between lesioning and implantation ('time of implantation') had no effects on the incidence of expression of $\sim 24$ hour and/or $\sim 20$ hour rhythms by chimeras. For quantitative purposes, presence or absence of a rhythm was coded as 1 or 0 , respectively, and we used the $F$ statistic to test for significance since it has been shown previously to yield probability statements close to those made by the chi-squared statistic in the evaluation of dichotomous data such as these 130/. Statistical analysis was done separately on the $\tau_{\mathrm{wt}}$ and $\tau_{\mathrm{ss}}$ host groups because we used a different number of lesion size categories for each genotype.

\section{Immunocytochemistry and histology}

Hamsters were anesthetized and perfused transcardially first with $30 \mathrm{ml}$ of heparinized saline (0.01 M phosphate buffered saline [PBS] at $\mathrm{pH} 7.4$ ) and then with $300 \mathrm{ml}$ of fixative (4\% paraformaldehyde, $15 \%$ picric acid in $0.01 \mathrm{M}$ PBS). The brains were removed and postfixed in the same fixative. After being cryoprotected in a $20 \%$ sucrose-PBS solution, the brains were sectioned (40 $\mu \mathrm{m})$ at $-23^{\circ} \mathrm{C}$ on a Reichart-Jung (model 2800) cryostat. Alternate sections were collected for immunocytochemistry with antibodies against glial fibrillary acidic protein (GFAP) and/or vasoactive intestinal peptide (VIP), which has been used previously as a marker for the SCN $/ 3,15,21 /$. These sections were stored at $-20^{\circ} \mathrm{C}$ in an antifreeze solution (60\% PBS, $40 \%$ ethylene glycol, 1\% PVP40) for periods lasting up to several months.

The perioxidase-antiperoxidase (PAP) method /26/ was used for immunocytochemistry. Freefloating sections were washed in PBS with $0.2 \%$ 
Triton X-100 (PBS-T) and then kept in $0.3 \% \mathrm{H}_{2} \mathrm{O}_{2}$ for 30 minutes to block endogenous peroxidases. The sections were washed again in PBS-T and then incubated in normal goat serum $(1: 30)$ for 30 minutes. Sections were then immediately transferred to primary antibody (GFAP [ICN], 1:1000; VIP [Incstar], 1:1000, diluted in PBS-T) and incubated for 72 hours at $4^{\circ} \mathrm{C}$. The sections were next washed in PBS-T and then incubated in a secondary antibody (GAM, 1:1000, or GAR, 1:100) for 1 hour. After washing in PBS-T the sections were incubated for another hour in PAP (1:100). Finally, the reactions were developed using $D A B$ as the chromogen, after which the sections were stored in Tris buffer, mounted on subbed slides, dehydrated through graded alcohols and kept in xylene overnight to remove lipid. They were then rehydrated and the $\mathrm{DAB}$ reaction was intensified with $4 \%$ osmium tetroxide. The sections were dehydrated once again and the GFAP immunostained sections were lightly counterstained with thionin. The slides were finally coverslipped with Permount, and the sections were examined under brightfield illumination. Our analysis included a determination of the extent of the host SCN lesion and the presence and location of surviving implants.

The brains of the lesion size group animals were analyzed using alternating $50 \mu$ sections stained with Nissl stain or for VIP immunoreactivity. The volume of remaining VIP reactive tissue was calculated by use of 3-D image reconstruction software.

\section{RESULTS}

\section{Behavioral analysis}

Figure 1 shows the record of a $\tau_{\mathrm{wt}}$ host that received a 2.5 second SCN lesion and a fetal $\tau_{\text {ss }}$ SCN transplant 23 days later. Visual inspection of the data plotted on a 24 hour time-base reveals that a bimodal 24 hour rhythm was retained by this animal after the lesion was made (L); the activity rhythm was phase shifted by the transplantation procedure (T), and its period subsequently was lengthened slightly. When a segment of these data is replotted on a 20 hour time-base it is obvious that there are no donor derived $\sim 20$ hour rhythms present in this record. this animal continued to express the rhythm generated by its own circadian oscillators and failed to express rhythmicity that we would expect to be generated by the circadian oscillators of the implanted donor SCN.

The data shown in Figure 2 are from a $\tau_{\mathrm{wt}}$ host which expressed the rhythm generated by its donor implant after losing expression of the rhythm originally generated by its own circadian oscillators. This animal received a 5 second SCN lesion $(\mathrm{L})$ and then a fetal $\tau_{\text {ss }}$ SCN transplant 31 days later $(T)$. The 24 hour time-base actogram shows a disrupted host rhythm after the time of the lesion that contains activity rhythms with ultradian periods. After the transplant, however, these rhythms are replaced by a single rhythm with the period of the donor (shown best when the data are replotted on a 20 hour timebase: Figure 2, right). No contribution from the host's circadian oscillators can be seen in this part of the record.

Figure 3 shows an example of the locomotor activity data of an animal expressing both host and donor rhythms. This $\tau_{\mathrm{ss}}$ host received a 10 second SCN lesion (L) and a fetal $\tau_{\mathrm{wt}}$ SCN transplant 42 days later $(\mathrm{T})$. In the 24 hour time-base actogram, one can observe a temporal zone, or window, within which wheelrunning activity occurs (days 65 to 154). This window has a period slightly less than 24 hours, which is consistent with what would be expected from $\tau_{\mathrm{wt}}$ circadian oscillators in the transplanted SCN. When the data from days 48 to 154 are replotted on a 19.6 hour time-base (Figure 3 , right), a similar window is observed, in this case with a period which would be expected from $\tau_{\mathrm{ss}}$ circadian oscillators located in the host SCN remnant. For additional examples of the locomotor records of temporal chimeras see $/ 27 /$.

The results of the analysis of the data from 151 lesioned and implanted animals are summarized in Tables 1 and 2. Table 1 summarizes the results of the behavioral analysis of all experiments in which $\tau_{\mathrm{wt}}$ animals were used as hosts, while Table 2 does the same for those experiments in which $\tau_{\text {ss }}$ animals were used as hosts. These data show that, in more than half of all cases, attempts to generate chimeras 


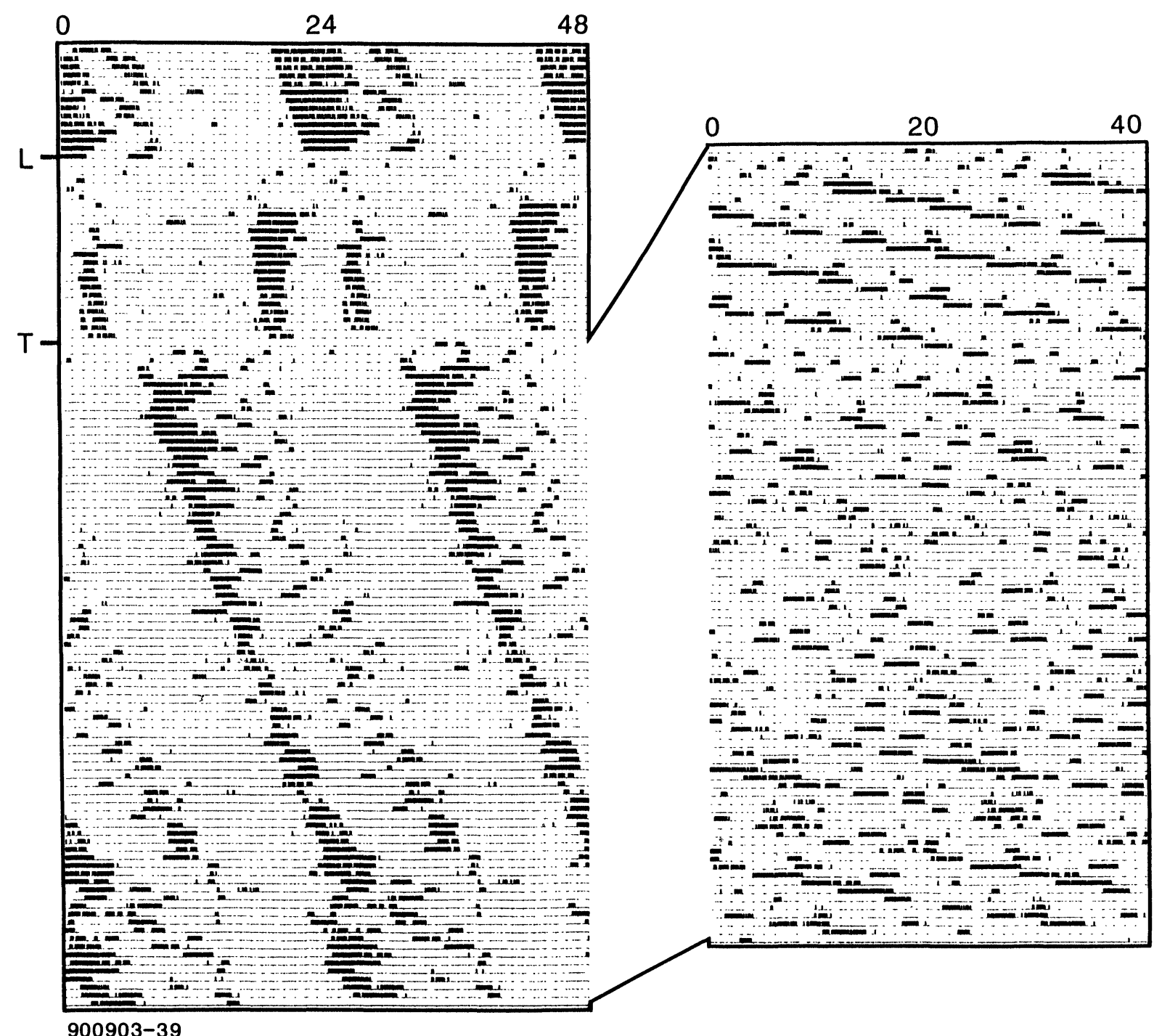

Fig. 1: Wheel-running data of a $\tau_{\mathrm{wt}}$ hamster maintained in constant darkness (DD), partially lesioned (2.5 sec) and given an ineffective $\tau_{\mathrm{ss}}$ SCN implant. The left panel shows the data double-plotted on the time-base that best demonstrates the period of the host's circadian rhythm, and the right panel shows a segment of the data, indicated by the lines connecting the two halves of the figure, replotted on the time-base that best indicates the period of rhythmicity that we would expect to be generated by the donor circadian oscillators. On each line of the actogram are plotted the locomotor activity data recorded during 2 consecutive cycles, and the second cycle's data are replotted on the line below the first day's data. Six minute time periods with more than 10 running wheel revolutions are represented by black boxes. A partial SCN lesion was made on the day marked $\mathbf{L}$, and a hypothalamic implant from a fetal $\tau_{\mathrm{ss}}$ donor was placed into the lesion cavity on the day marked $T$. the circadian rhythm generated by the host's circadian oscillators is maintained throughout the record. No expression of donor rhythmicity can be seen in the record when the data are replotted on a 20 hour time-base (right). 


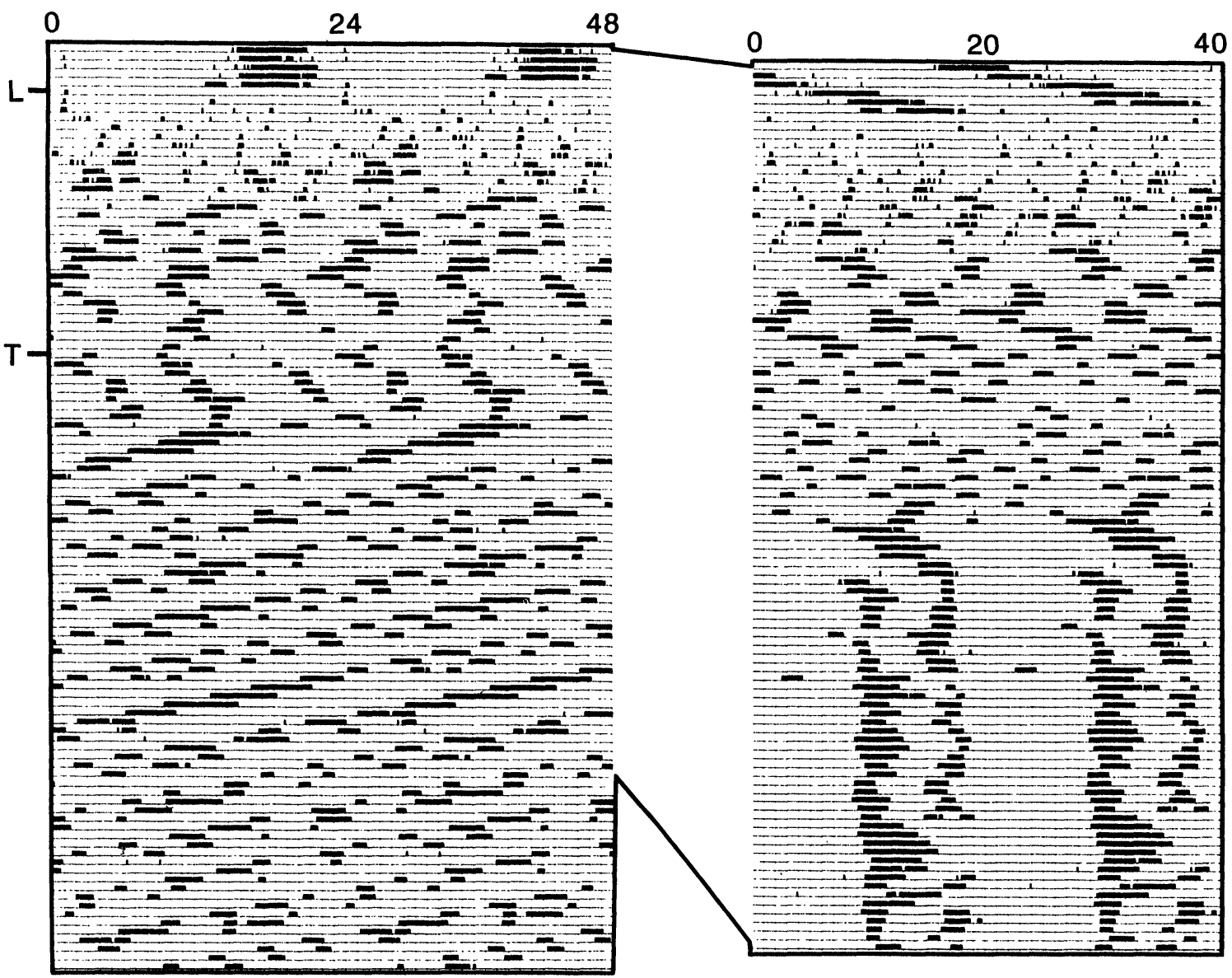

900326-11

Fig. 2: Wheel-running data of a lessioned $\tau_{w t}$ hamster which received an effective $\tau_{\mathrm{ss}} \mathrm{SCN}$ implant, plotted in the same manner as in Figure 1. An SCN lesion $(5 \mathrm{sec}$ ) was made on the day marked $\mathrm{L}$, and the implant was placed into the lesion cavity on the day marked T. Although the lesion was intended to be partial it completely eliminated the host's 24 hour circadian rhythm. After transplantation, however, a new rhythm with a period considerably shorter than 24 hours emerged in the record (left). When the data are replotted on a 20 hour time-base (right), it is clear that this shorter rhythm was generated by the donor circadian oscillators.

produced animals expressing only one rhythm, generated either by the remaining host circadian oscillators or by those of the donor. $\tau_{w t}$ hosts expressed only one rhythm (host or donor) in 61 out of the 105 animals that expressed any circadian rhythms; $\tau_{\mathrm{ss}}$ hosts expressed only one rhythm in 24 out of the 37 animals that expressed any circadian rhythms.

\section{The effect of current duration}

Statistical analysis of the data in Tables 1 and 2 reveals that the duration of current delivered during an SCN lesion determined the incidence of hostderived locomotor rhythmicity in both $\tau_{\mathrm{wt}}$ ( $\mathrm{p}=0.008)$ and $\tau_{\mathrm{ss}}(\mathrm{p}=0.002)$ host genotype groups. As would be expected, the incidence of host rhythm 


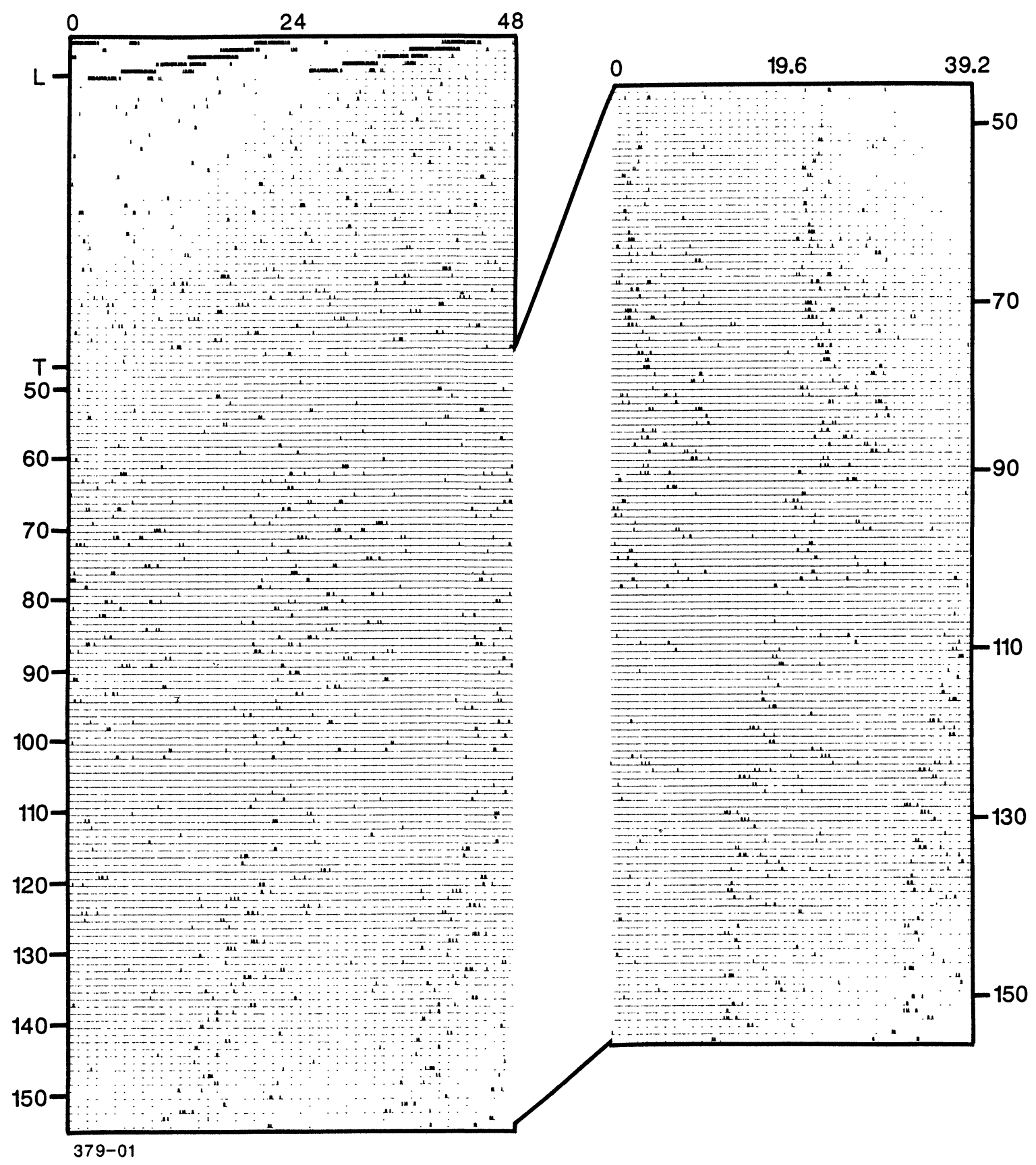

Fig. 3: Wheel-running data of a $\tau_{\mathrm{ss}}$ hamster expressing both host and donor rhythms, plotted in the same manner as in Figure 1. A partial SCN lesion was made on the day marked $L$, and a fetal $\tau_{w t}$ hypothalamic implant was placed into the lesion cavity on the day marked $T$. Within 20 days after transplantation a window pattern with a period slightly shorter than 24 hours emerges in the activity record (left). When the segment of data from days 45 to 156 are replotted on a 19.6 hour time-base (right), a similar window pattern with a period slightly shorter than 19.6 hours can be observed. The presence of these patterns when the data are plotted on both time-bases indicates that both host and donor circadian oscillators are present and functional in this animal. The low level of activity evident in this record occurred most often when $\tau_{s s}$ hamsters were given SCN lesions. 
TABLE 1

Wild-type hosts bearing homozygous mutant SCN transplants

\begin{tabular}{|c|c|c|c|c|c|c|}
\hline $\begin{array}{l}\text { Current } \\
\text { Duration, } \\
\text { Type of } \\
\text { Implant }\end{array}$ & $\mathrm{n}$ & $\begin{array}{c}\text { Express } \\
\text { Donor } \\
\text { Rhythm }\end{array}$ & $\begin{array}{c}\text { Express } \\
\text { Host } \\
\text { Rhythm }{ }^{1}\end{array}$ & $\begin{array}{l}\text { Express } \\
\text { One } \\
\text { Rhythm } \\
\text { Only }^{2}\end{array}$ & $\begin{array}{l}\text { Express } \\
\text { Both } \\
\text { Rhythms }{ }^{2}\end{array}$ & $\begin{array}{l}\text { Express } \\
\text { Neither } \\
\text { Host Nor } \\
\text { Donor } \\
\text { Rhythm }\end{array}$ \\
\hline \multirow{2}{*}{$\begin{array}{l}15 \text { sec. } \\
\text { Delayed }\end{array}$} & \multirow{2}{*}{14} & \multirow{2}{*}{$11(78 \%)$} & $7(50 \%)$ & \multirow{2}{*}{$8(57 \%)$} & \multirow{2}{*}{$6(43 \%)$} & \multirow[b]{2}{*}{0} \\
\hline & & & $9(64 \%)$ & & & \\
\hline \multirow{2}{*}{$\begin{array}{l}10 \mathrm{sec} . \\
\text { Delayed }\end{array}$} & \multirow{2}{*}{22} & \multirow{2}{*}{$17(77 \%)$} & $14(64 \%)$ & \multirow{2}{*}{$14(67 \%)$} & \multirow{2}{*}{$7(33 \%)$} & \multirow{2}{*}{$1(4 \%)$} \\
\hline & & & $11(50 \%)$ & & & \\
\hline \multirow{2}{*}{$\begin{array}{l}5 \mathrm{sec} . \\
\text { Delayed }\end{array}$} & \multirow[b]{2}{*}{16} & \multirow[b]{2}{*}{$14(88 \%)$} & $12(75 \%)$ & \multirow[b]{2}{*}{$4(25 \%)$} & \multirow[b]{2}{*}{$12(75 \%)$} & \multirow[b]{2}{*}{0} \\
\hline & & & $14(88 \%)$ & & & \\
\hline \multirow{2}{*}{$\begin{array}{l}2.5 \mathrm{sec} . \\
\text { Delayed }\end{array}$} & \multirow[b]{2}{*}{11} & \multirow[b]{2}{*}{$4(36 \%)$} & $10(91 \%)$ & \multirow{2}{*}{$9(82 \%)$} & \multirow{2}{*}{$2(18 \%)$} & \multirow[b]{2}{*}{0} \\
\hline & & & $9(82 \%)$ & & & \\
\hline $\begin{array}{l}15 \mathrm{sec} . \\
\text { Immediate }\end{array}$ & 3 & $3(100 \%)$ & $1(33 \%)$ & $2(67 \%)$ & $1(33 \%)$ & 0 \\
\hline $\begin{array}{c}10 \mathrm{sec} . \\
\text { Immediate }\end{array}$ & 18 & $11(61 \%)$ & $10(56 \%)$ & $9(60 \%)$ & $6(33 \%)$ & $3(17 \%)$ \\
\hline $\begin{array}{c}5 \mathrm{sec} . \\
\text { Immediate }\end{array}$ & 18 & $10(56 \%)$ & $13(72 \%)$ & $9(56 \%)$ & $7(44 \%)$ & $2(11 \%)$ \\
\hline $\begin{array}{c}2.5 \mathrm{sec} . \\
\text { Immediate }\end{array}$ & 9 & $3(33 \%)$ & $9(100 \%)$ & $6(67 \%)$ & $3(33 \%)$ & 0 \\
\hline Total & 111 & $73(66 \%)$ & $76(68 \%)$ & $61(59 \%)$ & $44(42 \%)$ & $6(5 \%)$ \\
\hline
\end{tabular}

${ }^{1}$ For delayed implant groups, the top number refers to the incidence of expression during the time after the SCN lesion and before the subsequent transplant. The bottom number is the incidence of rhythmicity after SCN transplant.

${ }^{2}$ Expressed as percentages of those animals expressing any circadian rhythm.

expression decreased as a function of increasing lesion current duration. In $\tau_{\mathrm{wt}}$ hosts rhythmicity was retained most often after lesions lasting 2.5 seconds, and in $\tau_{\text {ss }}$ hosts it was retained most often after 5 second lesions. In both groups, host rhythmicity was retained least often after animals received lesions lasting 15 seconds. This effect was clearest in the delayed implant groups during the time after a lesion and before the placement of a transplant.

Surprisingly, the duration of the current delivered during the placement of an SCN lesion also influenced the frequency of occurrence of donor-derived rhythms. In the $\tau_{\mathrm{wt}}$ host groups the incidence of donor rhythm expression increased as increased lesion current duration was used to make the host SCN lesion $(p=0.01)$. This relationship was graded in the cases of animals that received their implants immediately after lesions were made. In the delayed-implant group, however, the relationship was observed only after a threshold of current duration was surpassed; a 2.5 second lesion was insufficient to allow for expression of donor rhythmicity, but all current durations of 5 seconds or more allowed equivalent donor rhythm expression. A similar relationship between lesion current duration and donor rhythm expression was seen in the $\tau_{\mathrm{ss}}$ host data; however, this effect was statistically significant only with use of a one-tailed $t$-test $(p=0.044)$. 
TABLE 2

Homozygous mutant hosts bearing wild-type SCN transplants

\begin{tabular}{|c|c|c|c|c|c|c|}
\hline $\begin{array}{l}\text { Current } \\
\text { Duration, } \\
\text { Type of } \\
\text { Implant }\end{array}$ & $\mathrm{n}$ & $\begin{array}{l}\text { Express } \\
\text { Donor } \\
\text { Rhythm }\end{array}$ & $\begin{array}{c}\text { Express } \\
\text { Host } \\
\text { Rhythm }{ }^{1}\end{array}$ & $\begin{array}{l}\text { Express } \\
\text { One } \\
\text { Rhythm } \\
\text { Only }^{2}\end{array}$ & $\begin{array}{l}\text { Express } \\
\text { Both } \\
\text { Rhythms }{ }^{2}\end{array}$ & $\begin{array}{l}\text { Express } \\
\text { Neither } \\
\text { Host Nor } \\
\text { Donor } \\
\text { Rhythm }\end{array}$ \\
\hline \multirow{2}{*}{$\begin{array}{l}15 \mathrm{sec} . \\
\text { Delayed }\end{array}$} & \multirow[b]{2}{*}{4} & \multirow[b]{2}{*}{$2(50 \%)$} & $2(50 \%)$ & \multirow[b]{2}{*}{$3(75 \%)$} & \multirow[b]{2}{*}{$1(25 \%)$} & \multirow[b]{2}{*}{0} \\
\hline & & & $3(75 \%)$ & & & \\
\hline \multirow{2}{*}{$\begin{array}{l}10 \mathrm{sec} . \\
\text { Delayed }\end{array}$} & \multirow[b]{2}{*}{7} & \multirow[b]{2}{*}{$4(57 \%)$} & $5(71 \%)$ & \multirow[b]{2}{*}{$4(57 \%)$} & \multirow[b]{2}{*}{$3(43 \%)$} & \multirow[b]{2}{*}{0} \\
\hline & & & $6(86 \%)$ & & & \\
\hline \multirow{2}{*}{$\begin{array}{l}5 \mathrm{sec} . \\
\text { Delayed }\end{array}$} & \multirow[b]{2}{*}{6} & \multirow[b]{2}{*}{$2(33 \%)$} & $6(100 \%)$ & \multirow[b]{2}{*}{$4(67 \%)$} & \multirow[b]{2}{*}{$2(33 \%)$} & \multirow[b]{2}{*}{0} \\
\hline & & & $6(100 \%)$ & & & \\
\hline $\begin{array}{c}15 \mathrm{sec} . \\
\text { Immediate }\end{array}$ & 6 & $6(100 \%)$ & $1(17 \%)$ & $5(85 \%)$ & $1(17 \%)$ & 0 \\
\hline $\begin{array}{c}10 \mathrm{sec} . \\
\text { Immediate }\end{array}$ & 9 & $6(67 \%)$ & $6(67 \%)$ & $3(50 \%)$ & $3(50 \%)$ & $3(33 \%)$ \\
\hline $\begin{array}{c}5 \mathrm{sec} . \\
\text { Immediate }\end{array}$ & 8 & $3(38 \%)$ & $8(100 \%)$ & $5(67 \%)$ & $3(38 \%)$ & 0 \\
\hline Total & 40 & $23(58 \%)$ & $30(75 \%)$ & $24(65 \%)$ & $13(35 \%)$ & $3(8.5 \%)$ \\
\hline
\end{tabular}

${ }^{1}$ For delayed implant groups, the top number refers to the incidence of expression during the time after the SCN lesion and before the subsequent transplant. The bottom number is the incidence of rhythmicity after SCN transplant.

${ }^{2}$ Expressed as percentages of those animals expressing any circadian rhythm.

Table 3 includes the data from the group of hamsters used to examine the relationship between duration and size of SCN lesion. The data describing this relationship are also depicted graphically in Figure 4. Although the data are variable and the numbers in each group small, it is clear that SCN lesion size is roughly proportional to current duration.

\section{The effect of time of implantation after partial SCN lesion}

The time of implantation had no significant effect on the expression of donor rhythms in either the $\tau_{w t}(p=0.066)$ or $\tau_{s s}(p=0.262)$ host groups. Interestingly, however, in the $\tau_{\mathrm{ss}}$ but not the $\tau_{\mathrm{wt}}$ hosts the time of implantation affected the incidence of expression of host rhythmicity $(p=0.036)$. Host rhythms were retained after 10 or 15 second partial SCN lesions more often in the $\tau_{\mathrm{ss}}$ hosts which received delayed implants than in the corresponding hosts which received immediate implants.

Neither time of implantation nor duration of lesion current affected the frequency of expression of host and donor rhythms expressed together in either $\tau_{\mathrm{wt}}$ or $\tau_{\mathrm{ss}}$ host chimeras.

\section{SCN implants into unlesioned hosts}

Implants from $\tau_{\mathrm{ss}}$ donors placed into unlesioned $\tau_{\mathrm{wt}}$ hosts caused transient disruption of host circadian rhythmicity but in no case were donor derived rhythms observed $(n=8)$. The host rhythm disruptions were no different from those seen in control experiments in which cortex implants were placed into the third ventricle of unlesioned hosts. 


\section{TABLE 3}

Effect of current duration on size of SCN lesion

\begin{tabular}{|c|c|c|}
\hline $\begin{array}{c}\text { Current Duration } \\
(\mathrm{sec} .)\end{array}$ & $\begin{array}{c}\text { Volume of VIP } \\
\text { Immunoreactivity }\left(\mu^{3} \times 10^{8}\right) \\
\end{array}$ & $\begin{array}{c}\text { Circadian Rhythm } \\
(\mathrm{Y} / \mathrm{N})\end{array}$ \\
\hline Control (0) & 1.465 & $Y$ \\
\hline Sham $(0)$ & 0.985 & $\mathrm{Y}$ \\
\hline Sham $(0)$ & 1.630 & $\mathrm{Y}$ \\
\hline 2.5 & 1.641 & $Y$ \\
\hline 2.5 & 0.828 & $\mathrm{Y}$ \\
\hline 2.5 & 1.395 & $\mathrm{Y}$ \\
\hline 2.5 & 1.087 & $\mathrm{Y}$ \\
\hline 5 & 1.432 & $\mathrm{Y}$ \\
\hline 5 & 0 & $\mathrm{~N}$ \\
\hline 5 & 1.144 & $\mathrm{Y}$ \\
\hline 5 & 0.092 & $\mathrm{~N}$ \\
\hline 10 & 1.550 & $\mathrm{Y}$ \\
\hline 10 & 0 & $\mathrm{~N}$ \\
\hline 10 & 1.213 & $\mathrm{Y}$ \\
\hline 15 & 0 & $\mathbf{N}$ \\
\hline 15 & 1.270 & $\mathrm{~N}$ \\
\hline 15 & 0 & $\mathrm{~N}$ \\
\hline 15 & 0 & $\mathrm{~N}$ \\
\hline 15 & 0.807 & $\mathrm{~N}$ \\
\hline
\end{tabular}

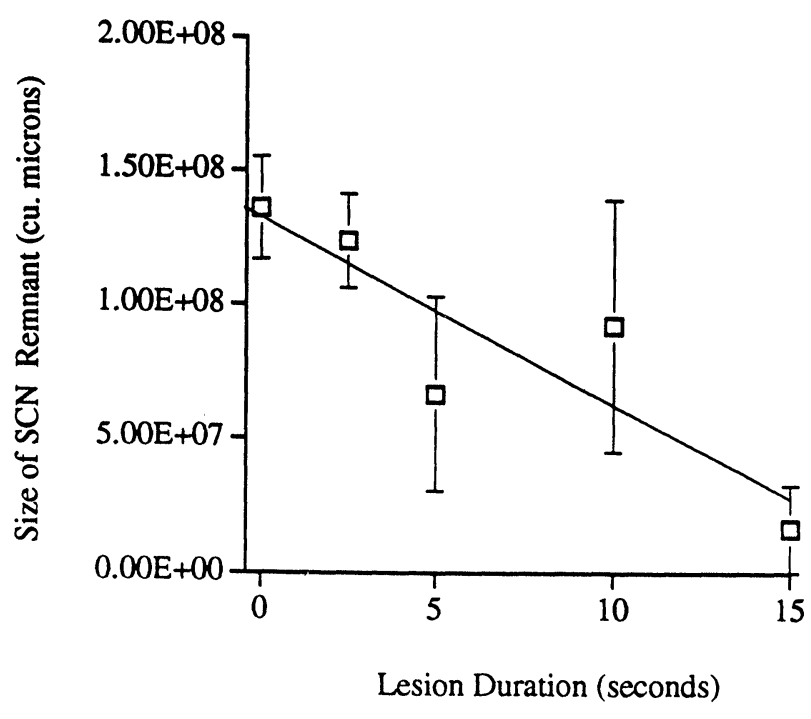

Figure 5 shows the record of a $\tau_{w t}$ host that received a $\tau_{\mathrm{ss}}$ fetal SCN implant on the day marked $\mathbf{T}$ without having received a prior SCN lesion. This record, which is typical of those produced by animals that received SCN transplants without a prior SCN lesion, shows that host ( 24 hour)

Fig. 4: The relationship between lesion current duration and the size of the $\mathrm{SCN}$ remnant depicted graphically. The data are listed in Table 3. Each point on the graph represents the mean \pm S.E. of the size of the SCN remnants measured for each current duration. Linear regression was used to fit a line with the equation $y=-7.02 E+06+1.3 E+08$ and with $\mathrm{r}^{2}=0.78$. 


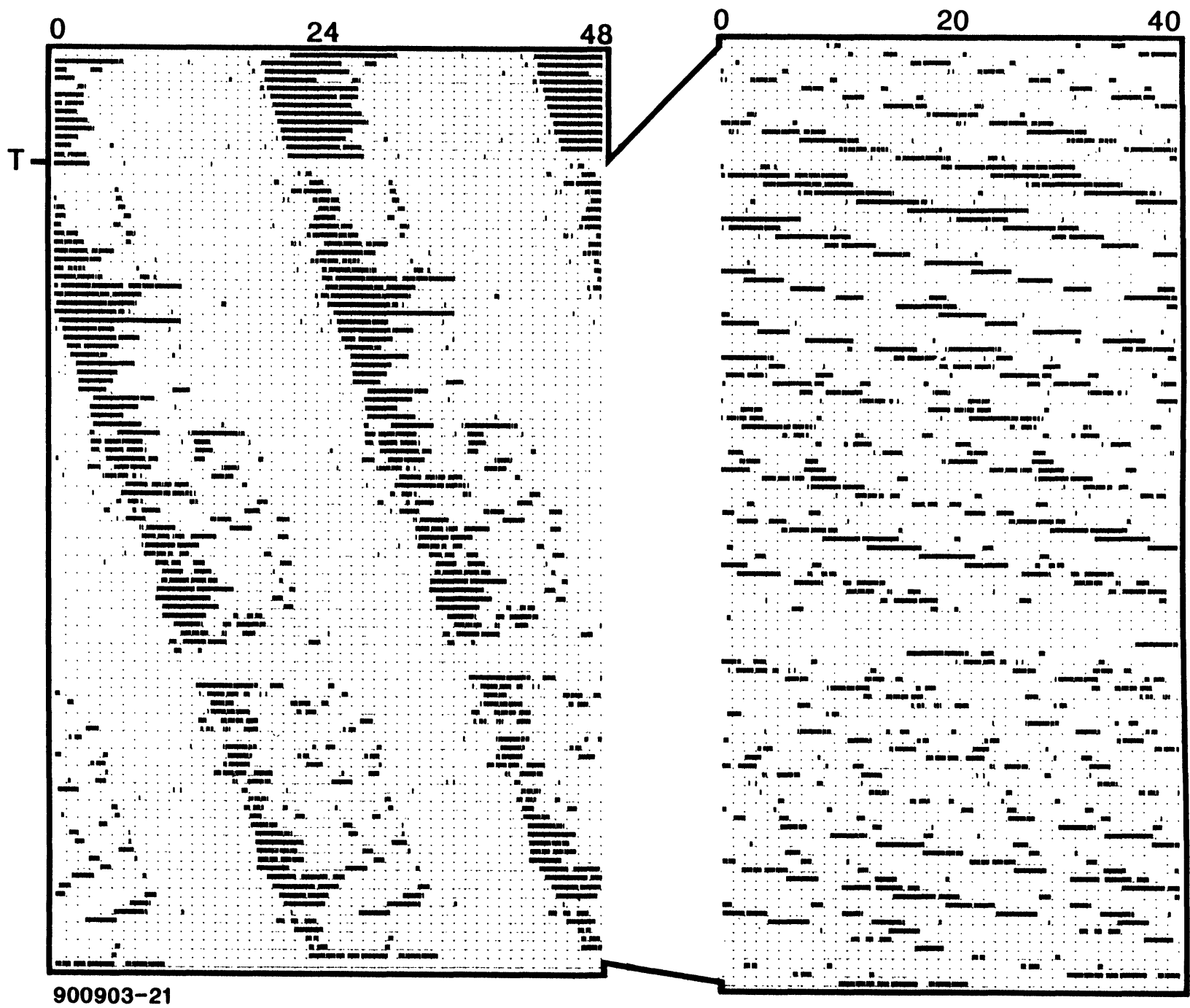

Fig. 5: Wheel-running data of a $\tau_{\mathrm{wt}}$ hamster that received a $\tau_{\mathrm{ss}}$ implant but no lesion, plotted in the same manner as in Figure 1 . The implant was placed into the third ventricle on the day marked T. The host's 24 hour circadian rhythm was maintained throughout the record (left). After transplantation, no donor rhythm can be seen in the 20 hour time-base actogram (right).

rhythmicity is maintained throughout the record, wile no donor ( 20 hour) rhythmicity is expressed at any time. Histological analysis of the brain of the animal whose record is shown in Figure 5 revealed the presence of a healthy appearing $\tau_{\mathrm{ss}} \mathrm{SCN}$ implant containing VIP immunoreactive cells located in the third ventricle directly above the unlesioned SCN of the $\tau_{\mathrm{wt}}$ host (Figures 6 and 7).

\section{Histological analysis}

The structural changes that occurred in the hypothalamus during the 3 to 4 months after an SCN lesion was made and an implant was placed, as well as the presence of donor tissue, made it difficult to use standard sections for the analysis of the size of the host SCN lesion, or to make even 


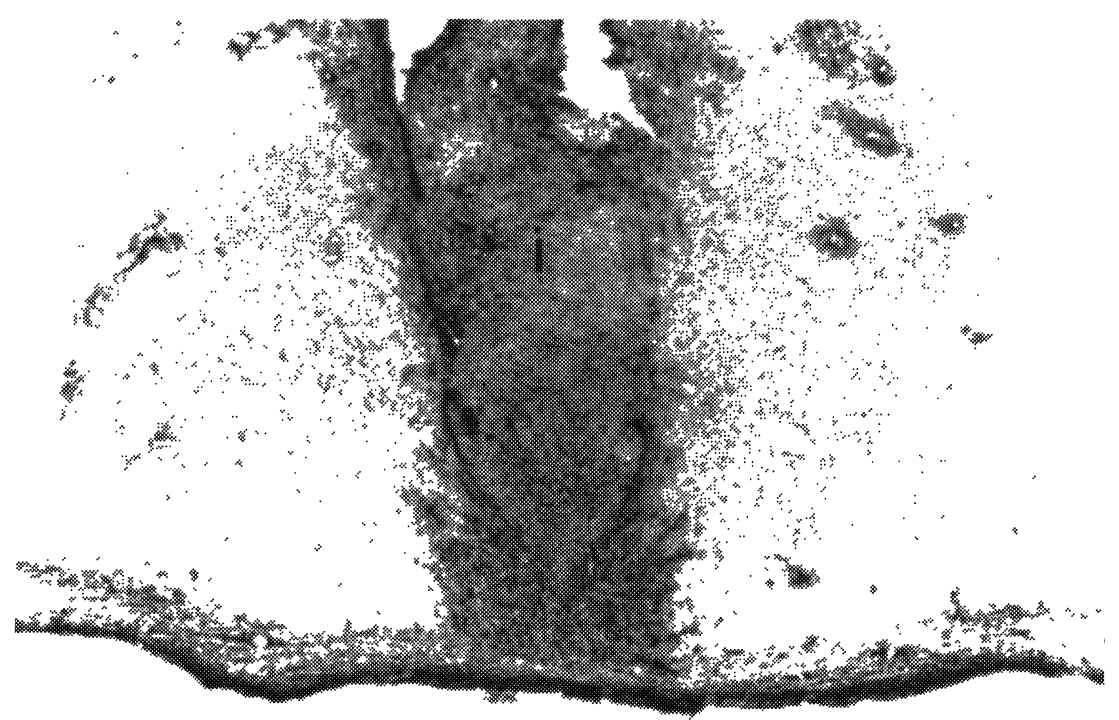

Fig. 6: A coronal section from the brain of the animal whose activity record is shown in Figure 5. This section was immunostained for GFAP, and then counterstained with thionin. The implant (i) can be seen within the third ventricle, above the intact host SCN which are darkly stained. Many areas along the host-implant border appear to be confluent, with clear interruption of the host's ependymal layer. (50x)

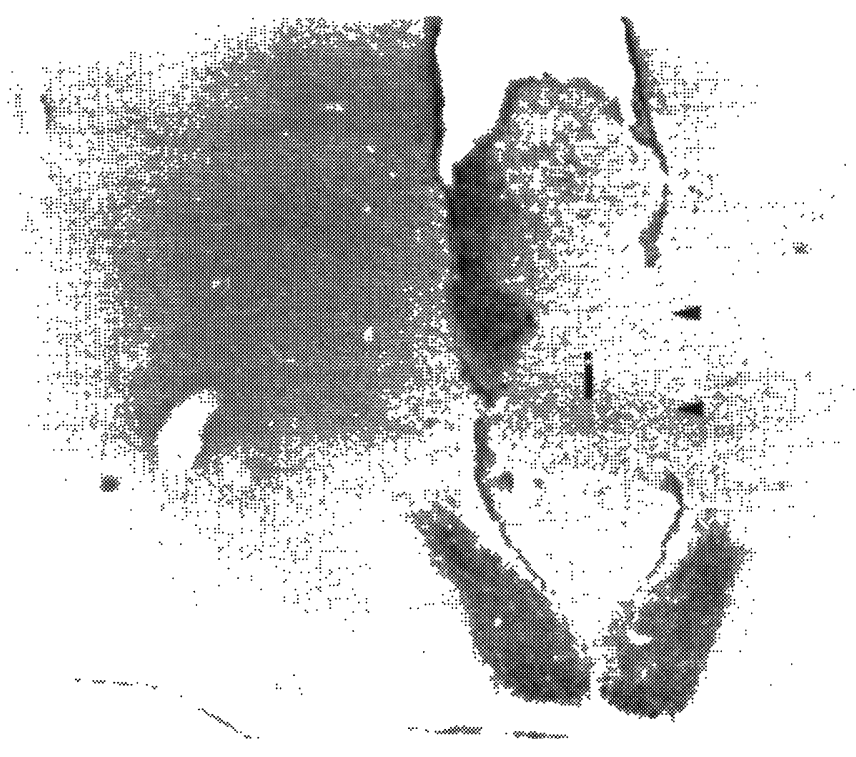

Fig. 7: An adjacent section to the one shown in Figure 6 was immunostained for the presence of VIP, which has been used as a marker for the SCN. The host's SCN are clearly stained, and a large area of VIP immunoreactivity is seen within the implant (i), at the host-graft border. This section also shows the confluence of host and graft in many areas (small arrowheads). (50x) 
gross estimates of its original size. On the other hand, the correlation between lesion current duration and reduction in the incidence of expression of host derived rhythmicity, indicates that lesion current duration may be accurately correlated with the degree of SCN damage.

We conducted a limited histological analysis in which we evaluated the effect of implant location on the incidence of expression of donor-derived rhythmicity. We restricted our analysis to $\tau_{\mathrm{wt}}$ host animals. We found that, in most cases, GFAP served as an excellent marker for the borders of the implants, facilitating our evaluation of implant location.

In spite of our attempts to place implants using the same stereotactic coordinates each time, the implants ended up in a number of locations. While there was little variation in the anterior-posterior location, there was considerably more variability along the superior-inferior axis. Nevertheless, we were able to assign each implant to one of two categories: A) implant in the dorsal third ventricle/Foramen of Monro region but not in the ventral part of the third ventricle (v. III); and B) implant in the ventral part of v. III and usually extending into the dorsal hypothalamus and/or midthalamic regions. Examples of implants categorized as A or B are shown in Figure 8. Table 4 lists the histological classifications made on sections from the brains of a subset of the hosts listed in Table 1. Those not included were lost to histological analysis for technical reasons (i.e. unexpected death of the host, or loss during histological preparation). We also have not included the cases $(n=3)$ in which the implant could not be found; in none of those cases was a donor rhythm detected in the locomotor activity record. In one case, we found an implant that was in cortex only; no donor rhythm was expressed in that animal's activity record. We verified that there was no sampling bias present in the subset of animals used for histological evaluation. The percentages of donor rhythm expression for each current duration and time of implantation group in this subset were similar to those found for the entire set of animals (Table 1). Furthermore, the statistically significant effect of current duration on the expression of donor rhythmicity held for this subset.
Statistical analysis of the data in Table 4 reveals that for all immediate and delayed implants considered together, location itself does not affect the ability of the donor SCN to express rhythmicity $(p=0.089)$. However, in spite of the fact that we have already shown that time of implantation after lesioning did not affect the incidence of donor expression, we found that it did modify the effect of implant location. The right half of Table 4 shows that far more delayed than immediate implants in location A were able to express rhythmicity $(p=0.003)$. The expression of rhythmicity by implants in location $B$ was no affected in a similar manner by the time of implantation $(p=0.373)$.

Interestingly, we determined that the time of implantation was at least in part responsible for determining the final location of the implant. Delayed implants were more likely to be found in location B $(30 / 46,65 \%)$ than were immediate implants $(14 / 38,37 \%)(p=0.009)$. On the other hand, lesion current duration did not affect implant location $(p=0.980)$.

\section{DISCUSSION}

Our results show that the response of the locomotor output system of hamsters to competing circadian inputs from host and donor circadian oscillators depends upon the amount of damage made to the host SCN. In support of this conclusion, we found that increasing the current duration used to produce an SCN lesion decreased the incidence of expression of host derived circadian locomotor rhythms and increased the incidence of expression of donor derived rhythms. The expression of donor rhythmicity approached $100 \%$ in the animals having lesions produced by the longest current durations, but was less than $40 \%$ in those having lesions produced by the shortest. Significantly, in no case was a donor derived rhythm seen when implants were placed into hosts that had not been lesioned.

In some of the animals in the delayed implant groups (Tables 1 and 2) the incidence of expression of host-derived rhythms changed after implants were placed. This change resulted in increased expression of host rhythms by some of the animals 

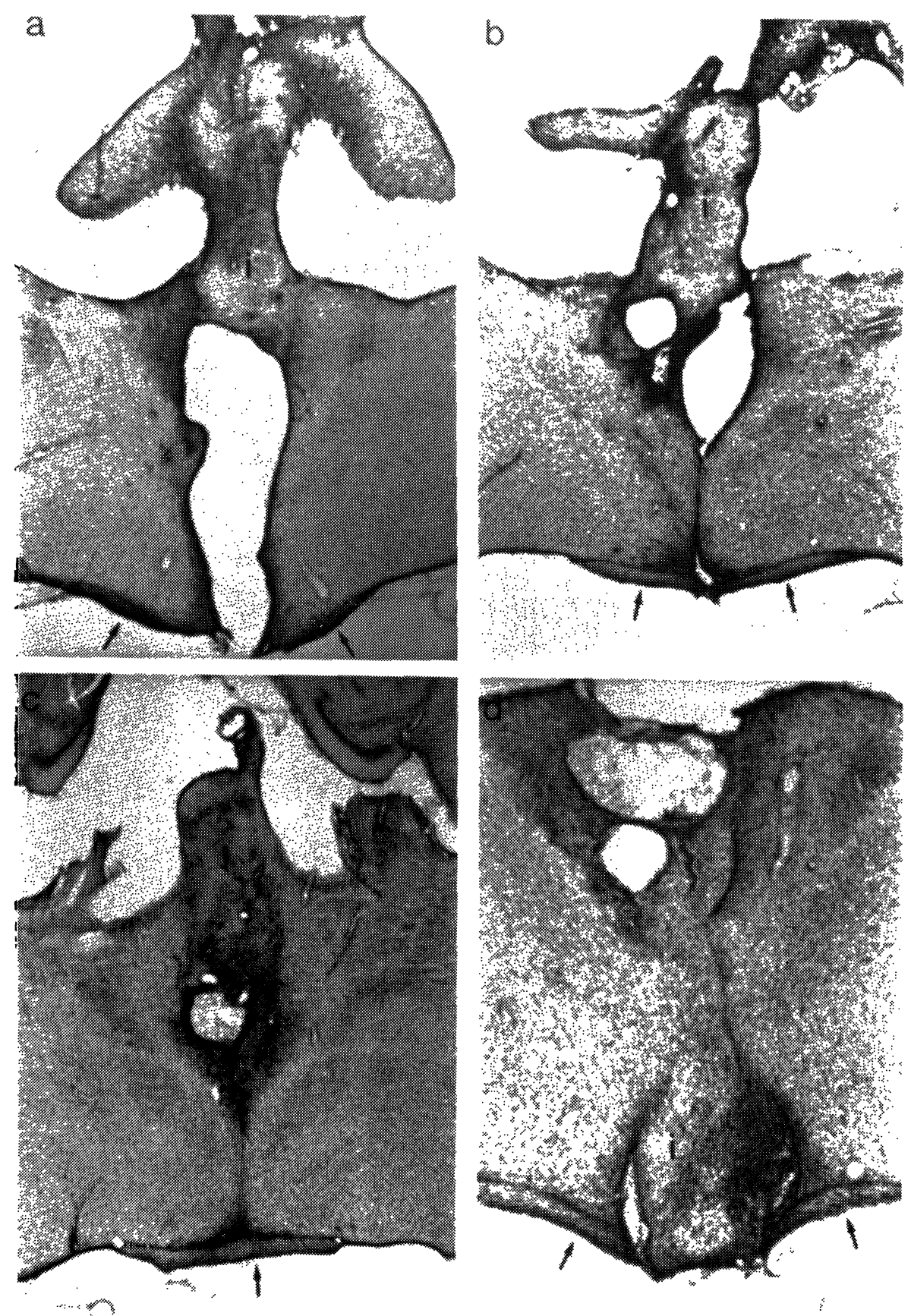

Fig. 8: Coronal sections from the brains of hamsters that expressed both host and donor rhythms, immunostained with GFAP and counterstained with thionin. Implants in panels (a), (b), and (c) can be seen in the dorsal part of $\mathbf{v}$. III with attachment to the thalamus, but without any direct contact with the ventral part of v. III or with the host's SCN remnant. These implants were classified as being in location A. The implant shown in panel (d) fills the ventral part of the third ventricle and abuts the host's SCN remnants. This implant was classified as being in location B. (i=implant; arrows indicate location of optic chiasm; (a), (b), (c) 25x; (d) 50x.) 
TABLE 4

Transplant location

\begin{tabular}{|c|c|c|c|c|c|}
\hline Location & $\mathrm{n}$ & $\begin{array}{c}\text { Express } \\
\text { Donor } \\
\text { Rhythm }\end{array}$ & $\begin{array}{l}\text { Timing } \\
\text { of } \\
\text { Implant }\end{array}$ & $\mathrm{n}$ & $\begin{array}{c}\text { Express } \\
\text { Donor } \\
\text { Rhythm }\end{array}$ \\
\hline \multirow[b]{2}{*}{ A } & \multirow{2}{*}{40} & \multirow{2}{*}{$24(60 \%)$} & Delayed & 16 & $14(88 \%)$ \\
\hline & & & Immediate & 24 & $10(42 \%)$ \\
\hline \multirow{2}{*}{ B } & \multirow{2}{*}{44} & \multirow{2}{*}{$34(77 \%)$} & Delayed & 30 & $22(73 \%)$ \\
\hline & & & Immediate & 14 & $12(86 \%)$ \\
\hline
\end{tabular}

and decreased expression in others. Several factors may act to decrease the incidence of host derived rhythmicity after an implant is placed, including additional damage to the SCN remnant, or the presence of a suppressive output from the implant $127 /$. On the other hand the incidence of expression might be increased by the release of trophic substances from embryonic implants /9/ that stimulate reorganization and reconnection of the remnant host circadian oscillators.

Interpretation of the effect of amount of lesion damage on the expression of donor rhythmicity is made difficult by a lack of knowledge of the mechanism(s) of output of the circadian signal(s) from the intact and transplanted SCN. If the circadian output from SCN transplants requires the formation of synaptic connections in the host hypothalamus, then a model of competition for synaptic sites between host and donor outputs could be used to explain the effect; the more SCN damage the fewer connections remain between the host's SCN and its targets and the more sites are open to the formation of connections by the donor SCN. Such an explanation may become more difficult to justify if only a hormonal output from the transplanted SCN is involved.

Previous SCN transplant work has been used to support hypotheses of either a hormonal mechanism or a synaptic mechanism of SCN output $/ 1,5,8,10$, 21/. Experiments describing the changes that occur after a neural lesion (for review see /17/) suggest that delayed, but not immediate, implants would be prevented from making neural connections by the physical boundary created by astrocytic proliferation and glial scarring. If the output mechanism requires the formation of projections and synapses, then delayed implants should have more difficulty that immediate implants in expressing rhythmicity. Therefore, the lack of influence of the time of implantation on the expression of rhythmicity in our data could be used to support the hypothesis of a hormonal output mechanism not likely to be affected by the formation of a glial scar. However, it has been shown that embryonic transplants can cause regression of the glial scar, presumably due to the release of trophic factors $/ 2,9 /$. Furthermore, in the hypogonadal mouse transplant model, it is quite clear that significant axonal outgrowth from the graft can pass through a glial scar imposed between the graft and host parenchyma $/ 22,23 /$. Therefore, delayed implants may be just as likely as immediate ones to form neural projections. Our data do not enable us to reject the idea that formation of synaptic connections is required for control of circadian locomotor behavior by the transplanted $\mathrm{SCN}$. Indeed, we have noticed a number of cases of especially rapid and robust expression of donor rhythmicity when implants were placed immediately after a small SCN lesion (Figure 9), which may reflect a rapid neural connection of the implant to the host in cases where there is no established glial scar.

The fact that the location of the implant does not affect expression of rhythmicity also bears on the issue of the output mechanism of SCN transplants. If expression of donor rhythmicity requires the formation of neural projections then one might expect that implants need to be close to their normal targets or projection pathways in order to make 


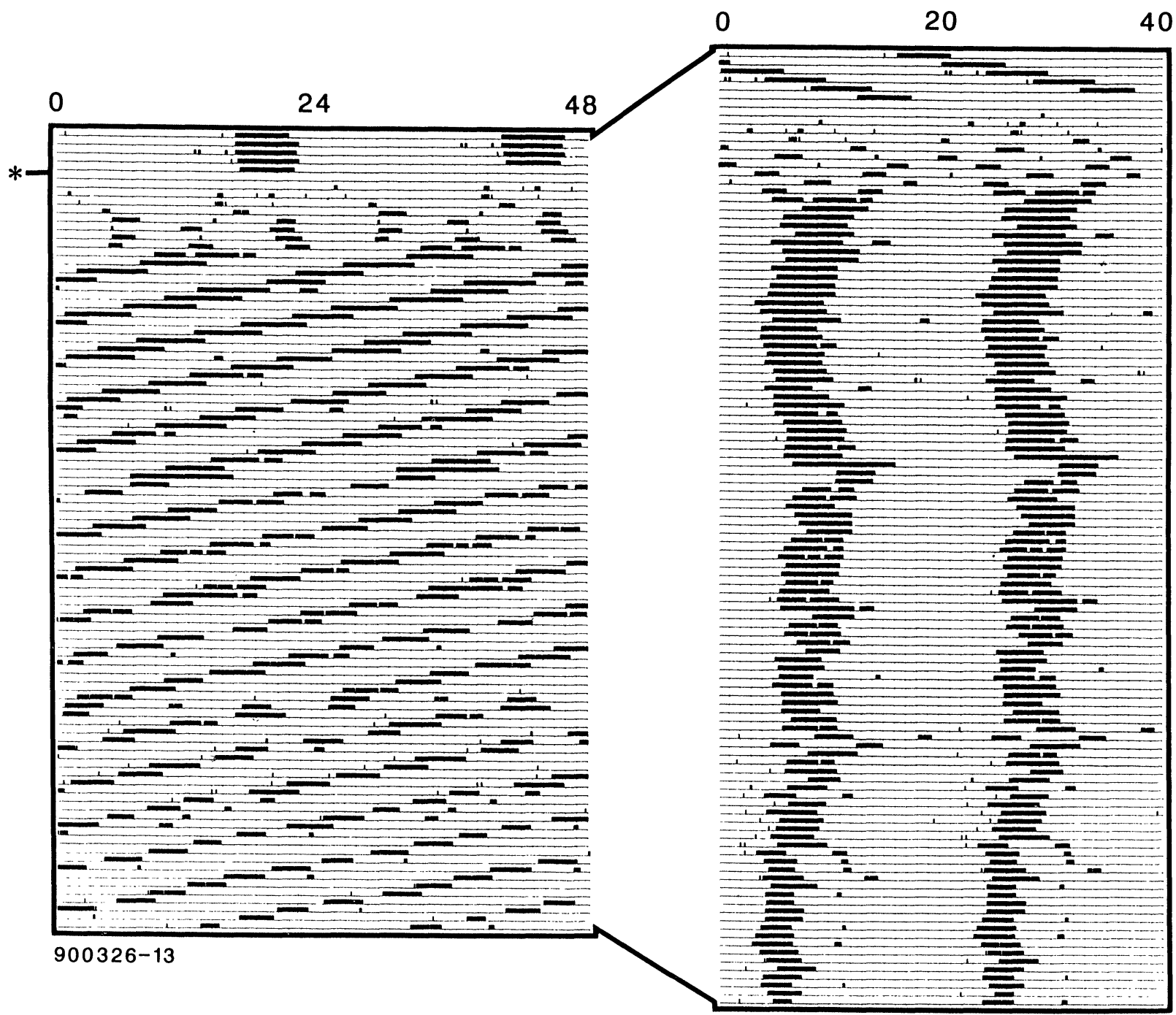

Fig. 9: Wheel-running data of a $\tau_{\mathrm{wt}}$ hamster that received an SCN lesion $(5 \mathrm{sec})$ and a fetal $\tau_{\mathrm{ss}}$ hypothalamic implant on the day marked * (immediate implant), plotted in the same manner as in Figure 1. A robust donor rhythm was expressed by this animal within 8 days following implantation; host rhythmicity was completely eliminated.

appropriate neural connections with the host (cf. /11/). However, the SCN normally projects to areas (the subparaventricular zone, paraventricular and midthalamic sites $/ 28,29 /$ ) which are near both locations $\mathrm{A}$ and $\mathrm{B}$. Thus, if the formation of synaptic connections between graft and host are involved in the control of rhythmicity by a transplanted SCN, these connections could be made directly to those targets listed above. Alternately, axons from the SCN might grow out to distant target sites along specific pathways that start near the host's SCN.

Unfortunately, traditional axonal tracing techniques cannot be applied to this problem because the implants cannot be visualized for 
precise and specific injections with tracers. The range of final locations for the implants all but eliminates the possibility of stereotaxic tracer injections. One promising approach to the analysis of neuronal outputs is through the use of immunocytochemical techniques to identify proteins intrinsic to, and specific for, certain types of neurons $/ 4,11,31,32 /$. In fact, Pickard and Sollars /13/ have demonstrated that mouse to hamster xenografts can be identified specifically, but the location and extent of the neuronal outputs has not yet been fully described or correlated with restoration of function.

\section{ACKNOWLEDGEMENTS}

The authors express their appreciation to Dr. J. Milton Adams, Department of Biomedical Engineering, for his assistance with the statistical analysis of our data. We are also grateful for the excellent technical assistance with the immunocytochemistry provided by Ed Shin, Trent Douglas, and Mike Frucht. This work was supported in part by AFOSR-90-0098 to M. M. and a Howard Hughes Medical Institute Undergraduate Award (J. Galef and E. Shin). Parts of the work included in this paper were presented at the annual meeting of the Society for Neuroscience, November 1991.

\section{REFERENCES}

1. Aguilar-Roblero RA, Morin LP, Moore RV. Is fetal SCN sufficient to induce rhythm recovery when transplanted to SCN-lesioned hamsters? Soc Neurosci Abstr 1988; 14: 24. 2.

2. Bernstein JJ, Goldberg WJ. Graft derived reafferentation of host spinal cord is not necessary for amelioration of lesioned-induced deficits: Possible role of migrating grafted astrocytes. Brain Res 1989; 22: 139-146.

3. Card JP, Moore RY. The suprachiasmatic nucleus of the golden hamster: immunohistochemical analysis of cell and fiber distribution. Neuroscience 1984; 13 (2): 415-431.

4. Charlton HM, Party DM, Jones A. Thy 1.1 and GnRH fibre output and physiological function in female hpg mice given preoptic area grafts from fetal AKR mice. In: Björklund A, Stenevi U, eds, Neural Grafting in the Mammalian CNS. New York: Elsevier, 1985; 637. 644.
5. DeCoursey PJ, Buggy J. Circadian rhythmicity after neural transplant to hamster third ventricle: specificity of suprachiasmatic nuclei. Brain Res 1989; 500: 263275.

6. Drucker-Colin R, Aguilar-Roblero A, GarciaHernandez F, Fernandez-Cancino F, Rattoni F. Fetal suprachiasmatic nucleus transplants: diurnal rhythm recovery of lesioned rats. Brain Res 1984; 311: 353357.

7. Gerkema MP, Groos GA, Daan S. Differential elimination of circadian and ultradian rhythmicity by hypothalamic lesions in the common vole, Microtus arvalis. J Biol Rhythms 1990; 5(2): 81-96.

8. Harrington ME, De Coursey PJ, Bruce D, Buggy J. Circadian pacemaker transplants into lateral ventricles fail to restore locomotor rhythmicity in arrhythmic hamsters. Soc Neurosci Abstr 1987; 13: 65.9.

9. Houle J, Reier P. Transplantation of fetal spinal cord tissue into the chronically injured adult rat spinal cord. J Comp Neurol 1988; 269: 535-547.

10. Lehman M, Silver R, Gladstone W, Kahn R, Gibson M, Gittman E. Circadian rhythmicity restored by neural transplant. Immunocytochemical characterization of the graft and its integration with the host brain. J Neurosci 1987; 7 (6): 1626-1638.

11. McLoon SC, Lund RD. Specific projections of retina transplanted to rat brain. Exp Brain Res 1980; 40: 273-282.

12. Moore RY, Eichler V. Loss of a circadian adrenal corticosterone rhythm following suprachiasmatic lesions in the rat. Brain Res 1972; 42: 201-206.

13. Pickard GE, Sollars PJ. Time-course of fiber outgrowth from fetal anerior hypothalamic (AH) heterografts. Soc Neurosci Abstr 1991; 17: 262.3.

14. Pickard GE, Turek RW. Effects of partial destruction of the suprachiasmatic nuclei on two circadian parameters: wheel-running activity and short-day induced testicular regression. J Comp Physiol 1985; A156: 803-815.

15. Ralph MR, Foster RG, Davis FC, Menaker M. Transplanted suprachiasmatic nucleus determines circadian period. Science 1990; 247: 975-978.

16. Ralph MR, Menaker M. A mutation of the circadian system in golden hamsters. Science 1988; 241: 12251227.

17. Reier P, Houle J. The glial scar: Its bearing on axonal elongation and transplantation approaches to CNS repair. In: Waxman SG, ed, Advances in Neurology, Vol 47: Functional Recovery in Neurologic Disease. New York: Raven Press, 1988.

18. Rusak B. The role of the suprachiasmatic nuclei in the generation of circadian rhythms in the golden hamster, Mesocricetus auratus. J Comp Physiol 1977; 118: 145164.

19. Rusak B, Zucker I. Neural regulation of circadian rhythms. Physiol Rev 1979; 59: 449-526. 
20. Sawaki Y, Nihonmatsu I, Kawamura H. Transplantation of the neonatal suprachiasmatic nuclei into rats with complete bilateral suprachiasmatic lesions. Neuorsci Res 1984; 1: 67-72.

21. Silver R, Lehman MN, Gibson M, Gladstone WR, bittman EL. Dispersed cell suspensions of fetal SCN restore circadian rhythmicity in SCN-lesioned adult hamsters. Brain Res 1990; 525: 45-58.

22. Silverman A-J, Zimmermann EA, Gibson MJ, Perlow MJ, Charlton HM, Kokoris GJ, Krieger DT, Implantation of normal fetal preoptic area into hypogonadal mutant mice: temporal relationships of the growth of gonadotropin-releasing hormone neurons and the development of the pituitary testicular axis. Neuroscience 1985; 16: 69-84.

23. Silverman RC, Gibson MJ, Silverman A-J. Application of a fluoresencet dye to study connectivity between third ventricular preoptic area grafts and host hypothalamus. J Neurosci Res 1992; 31: 156-165.

24. Sokolove PG, Bushell WN. The chi square periodogram. Its utility for analysis of circadian rhythms. J Theor Biol 1978; 72: 131-160.

25. Stephan F, Zucker I. Circadian rhythms in drinking behavior and locomotor activity of rats are eliminated by hypothalamic lesions. Proc Natl Acad Sci USA 1972; 69 (6): 1583-1586.

26. Sternberger LA. Immunocytochemistry, 2nd Ed. New York: John Wiley and Sons, 1979.
27. Vogelbaum MA, Menaker M. Temporal chimeras produced by hypothalamic transplants. J Neurosci 1992; 12 (9): 3619-3627.

28. Watts AG, Swanson LW. Efferent projetions of the suprachiasmatic nucleus: II. Studies using retrograde transport of fluorescent dyes and simultaneous peptide immunohistochemistry in the rat. J Comp Neurol 1987; 258: 230-252.

29. Watts AG, Swanson LW, Sanchez-Watts G. Efferent projections of the suprachiasmatic nucleus: I. Studies using anterograde transports of Phaseolus vulgaris leucoagglutinin in the rat. J Comp Neurol 1987; 258: 204-229.

30. Winer BJ. Statistical Principles in Experimental Design, 2nd Ed. New York: McGraw-Hill 1971.

31. Zhou C-F, Li Y, Raisman G. Embryonic entorhinal transplants project selectively to the deafferented entorhinal zone of adult mouse hippocampi, as demonstrated by the use of Thy- 1 allelic immunohistochemistry. Effect of timing of transplantation in relation to deafferentiation. Neuroscience 1989; 32 (2): 349-362.

32. Zhou C-F, Raisman G, Morris RJ. Specific patterns of fibre outgrowth from transplants to host mice hippocampi, shown immunohistochemically by the use of allelic forms of Thy-1. Neuroscience 1985; 16 (4): 819-833. 

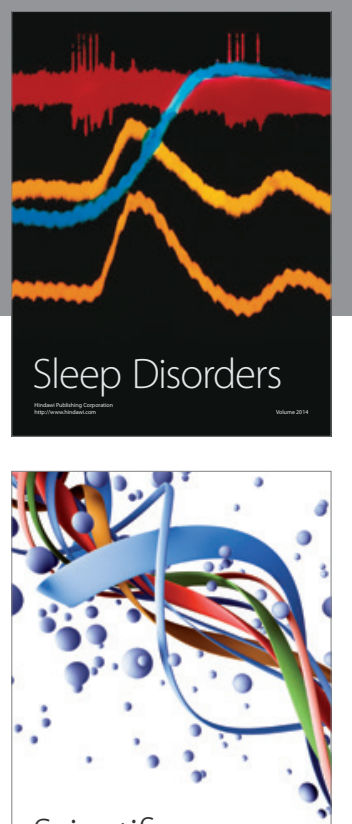

Scientifica
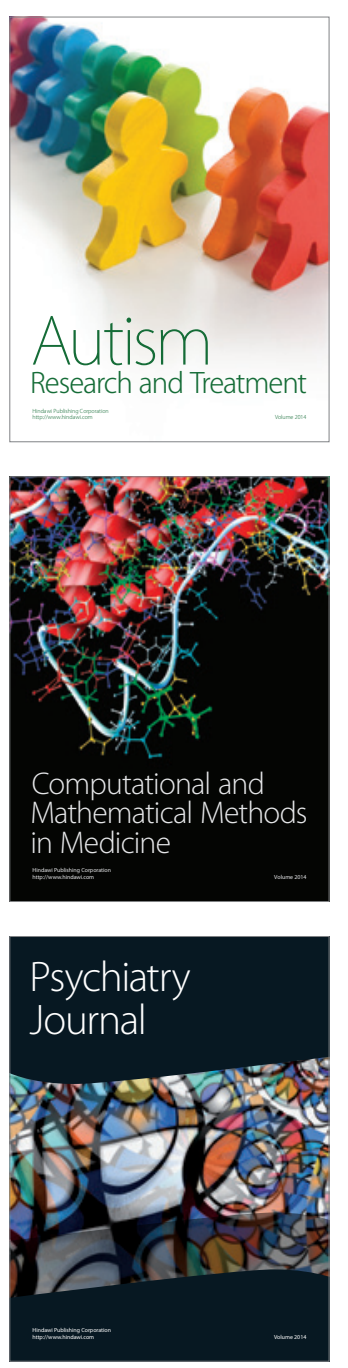
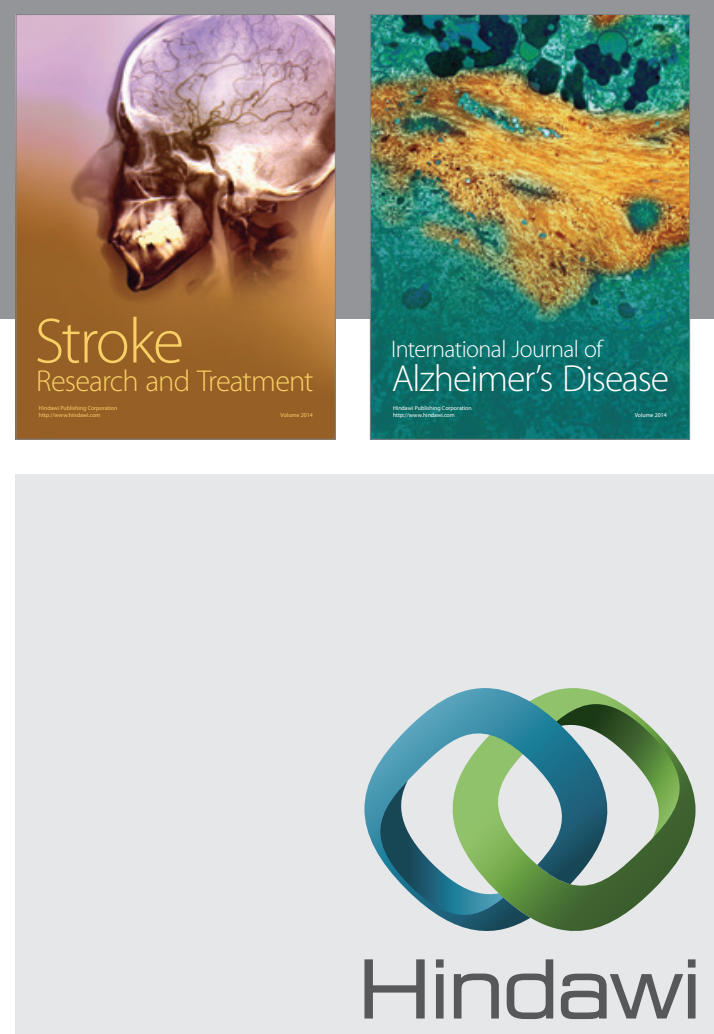

Submit your manuscripts at

http://www.hindawi.com
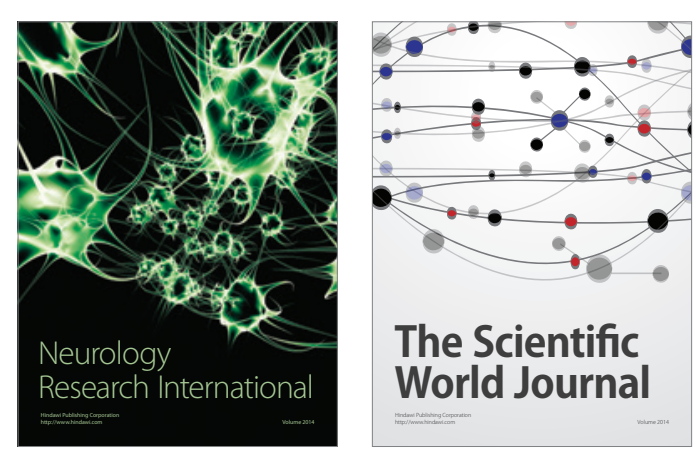

The Scientific World Journal

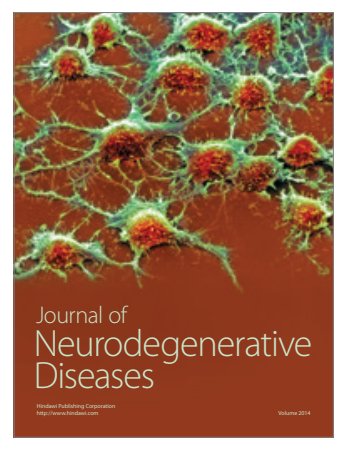

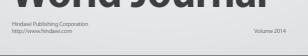

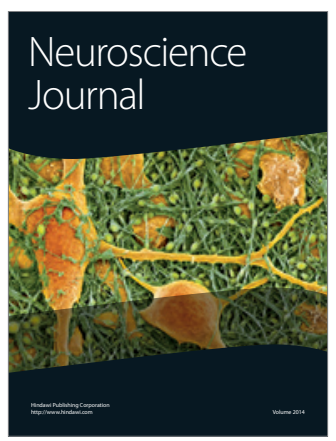

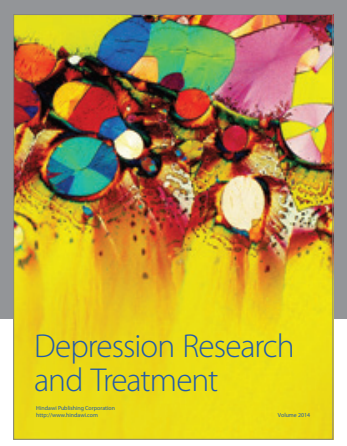
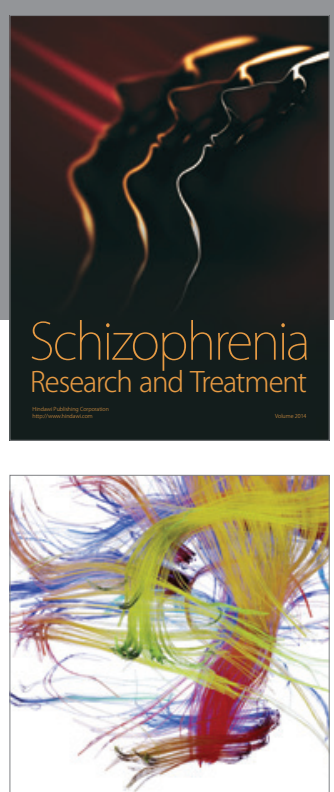

Brain Science

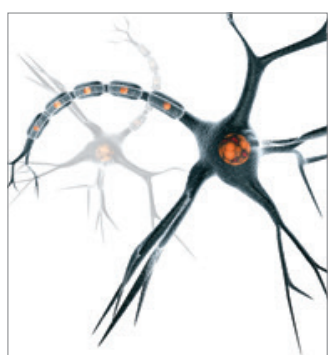

Neural Plasticity
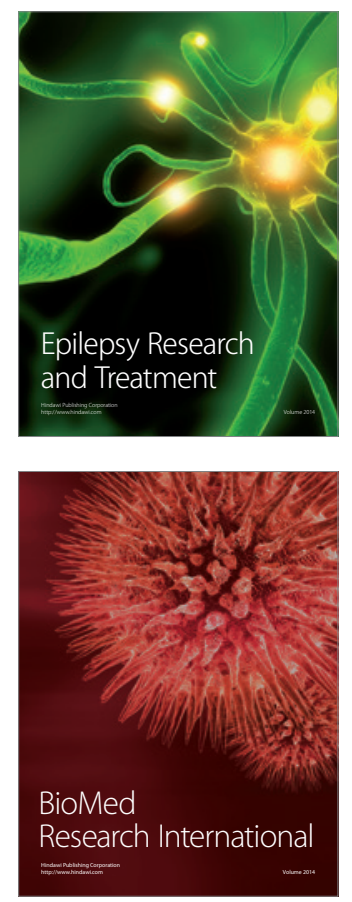

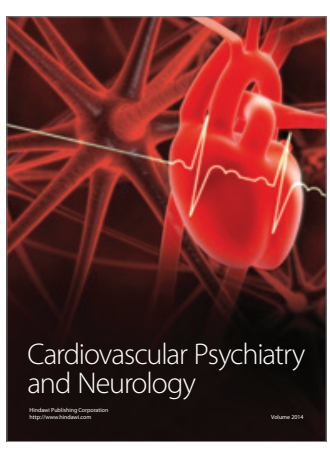

Parkinson's

Disease
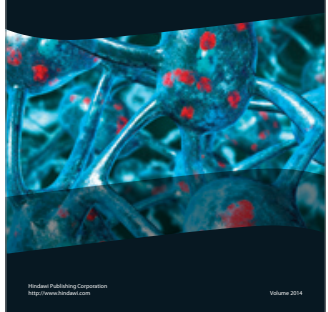